\title{
Original
}

\section{Evaluation of an Improved Bioluminescence Assay for the Detection of Bacteria in Soy Milk}

\author{
YOHEI SHINOZAKI ${ }^{*}$, JUN SATO', TOSHINORI IGARASHI', \\ SHIGEYA SUZUKI ${ }^{3}$, KAZUNORI NISHIMOTO', AND YASUHIRO HARADA ${ }^{1}$ \\ ${ }^{1}$ Research and Development Division, Kikkoman Corporation, \\ 399 Noda, Noda, Chiba 278-0037, Japan \\ 2 Department of Food Life Sciences, Faculty of Life Sciences, Toyo University, \\ 1-1-1 Izumino, Itakura-machi, Ora-gun, Gunma 374-0193, Japan \\ ${ }^{3}$ Kikkoman Biochemifa Company, 2-1-1, Nishi-Shinbashi, Minato-ku, Tokyo 105-0003, Japan
}

Received 7 July, 2012/Accepted 21 August, 2012

\begin{abstract}
Because soy milk is nutrient rich and nearly neutral in $\mathrm{pH}$, it favors the growth of microbial contaminants. To ensure that soy milk meets food-safety standards, it must be pasteurized and have its sterility confirmed. ATP bioluminescence assay has become a widely accepted means of detecting food microorganisms. However, the high background bioluminescence intensity of soy milk has rendered it unsuitable for ATP analysis. Here, we tested the efficacy of an improved pre-treated bioluminescence assay on soy milk. By comparing background bioluminescence intensities obtained by the conventional and improved methods, we demonstrated that our method significantly reduces soy milk background bioluminescence. The dose-response curve of the assay was tested with serial dilutions of Bacillus sp. culture. An extremely strong log-linear relation between the bioluminescence intensity relative light units and colony formation units CFU/ml emerged for the tested strain. The detection limit of the assay was estimated as $5.2 \times 10^{3} \mathrm{CFU} / \mathrm{ml}$ from the dose-response curve and an imposed signal limit was three times the background level. The results showed that contaminated samples could be easily detected within $24 \mathrm{~h}$ using our improved bioluminescence assay.
\end{abstract}

Key words : Bioluminescence assay / ATP / Soy milk/Bacillus.

\section{INTRODUCTION}

Soy foods contain multiple nutritive substances such as proteins, unsaturated fatty acids, isoflavones, oligosaccharides, mineral substances, free amino acids and polypeptides (Golbitz, 1995). Soy beans and their derivatives are an important part of traditional Asian diets. Food products derived from soy include soy oil, soy flour, soy milk, tofu, okara, yuba, tempeh, miso, soy sauce and natto. Several epidemiological and clinical studies have highlighted the potential health benefits of such products (Xiao, 2008). For in-

*Corresponding author. Tel: +81-4-7123-5522, Fax: +81-47123-5947, E-mail : yshinozaki (a)mail.kikkoman.co.jp stance, consumption of soy foods can alleviate a number of chronic diseases, such as cardiovascular diseases (Clarkson, et al., 1995), cancer (Peterson and Barnes, 1991; Lee et al., 1991), and osteoporosis (Knight and Eden, 1996). Recently the Japanese soy milk market has been expanding steadily as consumers become increasingly health conscious.

In Japan, various types of beverages are aseptically packed into polyethylene terephthalate bottles (Sato, 2010) or Tetra Brik. In the case of soy milk, Tetra Brik is typically used for small containers (200 ml) (Steve, 1989), while an aseptic aluminum laminated bag is used for large containers (over 1000 $\mathrm{ml}$ ). Because soy milk is nutrient rich and near neutral in $\mathrm{pH}$, it favors the growth of contaminating microorganisms, which must be removed by heat 
pasteurization (Kwok and Niranjan, 1995). Moreover, it is necessary to confirm the sterility of packed soy milk to ensure that food-safety regulations are satisfied.

To detect contaminating bacteria, food products are conventionally incubated for 1 to 2 wk, followed by statistical sampling for visible signs of bacterial contamination (Gavin and Weddig, 1995). Assessing the incubated products involves the time-consuming and labor-intensive procedures of visual inspection and standard plate counts that take at least 2 to $3 \mathrm{~d}$. Therefore, faster and easier methods that provide reliable results are urgently required.

ATP bioluminescence assay is a widely accepted rapid method to estimate counts or biological conditions of microorganisms in foods, beverages, microbiological media and other environments (Hattori et al., 1998; Ukuku et al., 2001; Samkutty et al., 2001; Venkateswaran et al., 2003; Ukuku et al., 2005; Chen and Godwin 2006; Shirai et al., 2009). ATP bioluminescence assay is based on the bioluminescence reaction between firefly luciferase-luciferin and ATP. The light measured by a luminometer is assumed proportional to the amount of ATP present in the microbial cells. To estimate the microorganism number, not only must intracellular ATP be extracted, but also extracellular ATP must be removed prior to the bioluminescence reaction. Previously, we have developed an effective intracellular ATP releasing technique (Hattori et al., 2003) and an extracellular ATP eliminating reagent (Sakakibara et al., 1997) in our quest for a highly sensitive, rapid and easilyapplied bioluminescence assaying method. Extracellular ATP elimination occurs via enzymatic reactions between adenosine phosphate deaminase and apyrase. In these reactions, ATP and its related adenosine derivatives are rapidly converted to inosine monophosphate. However, soy milk is known to contain high concentrations of extracellular ATP, speculated to be attached to soy milk components such as proteins, fibers and cell debris. Because such components physically inhibit enzymatic reactions, they probably present a barrier to extracellular ATP removal. Extracellular ATP in the bioluminescence reaction is a source of noise, leading to over-estimates of intracellular ATP levels and lowered sensitivity for microorganism detection (Sakakibara et al., 1997).

Previously, we developed an improved pretreatment method to reduce the amount of extracellular ATP in soy milk. The objective of the present study was to evaluate and demonstrate the usefulness of the improved bioluminescence assay. Commercially available soy milk products were used to compare the background bioluminescence intensities between the conventional and novel methods. The efficacy and high sensitivity of the pretreated assay was confirmed using spore-forming bacteria (which are major sources of beverage contamination). The improved regime, unlike the conventional bioluminescence assay, could detect minimal levels of spores in soy milk.

\section{MATERIALS AND METHODS}

\section{Samples}

Aluminum aseptic bags ( $3 \mathrm{~L}$ ) containing sterile soy milk were purchased from a soy milk manufacturer. Commercially available soy milk (plain, original, tea, cocoa, sesame, coffee flavor) in $200 \mathrm{ml}$ Tetra Brik packages were purchased from a supermarket.

\section{Strains}

The influence of pretreatment on the bioluminescence intensity was tested on Bacillus sp. W01 isolated from soybean powder, Bacillus subtilis $\mathrm{ATCC} 051^{\top}$, B. licheniformis NBRC $12200^{\top}, B$. coagulans NBRC12583 ${ }^{\top}$ and $B$. megaterium NBRC15308'.

\section{Spore preparation and culture conditions}

Bacillus sp. WO1 was inoculated into Trypticase soy broth (TSB; EIKEN Co., Japan) and incubated at $30^{\circ} \mathrm{C}$ overnight. A $100 \mu \mathrm{l}$ aliquot of vegetative cell culture was spread onto a Trypticase soy agar (TSA; EIKEN Co., Japan) plate and incubated upside-down for 1 wk at $30^{\circ} \mathrm{C}$. This plate was monitored for spore formation by phase-contrast microscopy. Following incubation, spores were harvested with $5 \mathrm{ml}$ of cold sterile ultrapure water. A spore suspension was heated at $80^{\circ} \mathrm{C}$ for $15 \mathrm{~min}$. The heated spore suspension was collected by centrifugation at $8,000 \times g$ at $4^{\circ} \mathrm{C}$ for $15 \mathrm{~min}$ and washed twice with $10 \mathrm{ml}$ of cold sterile ultrapure water. The spore preparation was stored in sterile water at $4^{\circ} \mathrm{C}$. Prior to use, the spore preparation was serially diluted with sterile ultrapure water. In this paper, all serial dilutions range from $10^{2}$ to $10^{5}$, diluted by a factor of 10 each time, unless otherwise specified. The spore count $(\mathrm{CFU} / \mathrm{ml})$ was determined by plating $100 \mu \mathrm{l}$ of diluted samples on TSA plates in triplicate. Colonies were counted following incubation at $30^{\circ} \mathrm{C}$ for $24 \mathrm{~h}$.

To confirm whether pretreatment influenced the bioluminescence intensity, vegetative cells of sporeforming bacteria were prepared in the following manner. B. subtilis ATCC6051 $1^{\top}$, B. licheniformis $\mathrm{NBRC} 12200^{\top}$, B. coagulans NBRC $12583^{\top}$ and $B$. megaterium NBRC15308 ${ }^{\top}$ were inoculated in TSB and incubated at $37^{\circ} \mathrm{C}$ overnight. A $100 \mu \mathrm{l}$ aliquot of each culture was then inoculated into $10 \mathrm{ml}$ of TSB 
and incubated at $37^{\circ} \mathrm{C}$ for $18-24 \mathrm{~h}$ to reach the stationary phase. Cultures were prepared for the bioluminescence assay as described below. Colony counts $(\mathrm{CFU} / \mathrm{ml})$ were determined by plating $100 \mu \mathrm{l}$ of serially diluted samples onto triplicate TSA plates. The resulting colonies were counted after incubation at 37 ${ }^{\circ} \mathrm{C}$ for $24 \mathrm{~h}$.

\section{Preparation of spore-contaminated samples}

Bacillus sp. W01 spores were suspended in sterile ultrapure water (approximately $8.0 \times 10^{2} \mathrm{CFU} / \mathrm{ml}$ of spores), and a $100 \mu \mathrm{l}$ sample was injected into $3 \mathrm{~L}$ soy milk aseptic bags by a syringe attached to a needle (TERMO, Japan). Contaminated soy milk bags were mixed in a shaking incubator (TAITEC, Bioshaker) at room temperature, $220 \mathrm{rpm}$ for $10 \mathrm{~min}$. Contaminated soy milk was divided into sterile $50 \mathrm{ml}$ disposable Falcon tubes. Tubes were incubated at $35^{\circ} \mathrm{C}$ for $18,24,48$ or $72 \mathrm{~h}$ (20 tubes per incubation time). Bioluminescence and plate count assays were applied to incubated soy milk tubes as described below.

Samples were serially diluted in Dulbecco's phosphate-buffered saline. Diluted samples $(100 \mu \mathrm{I})$ were plated onto TSA plates, and resulting colonies were counted after incubation at $35^{\circ} \mathrm{C}$ for $24 \mathrm{~h}$. Counts were represented as colony forming units $(\mathrm{CFU} / \mathrm{ml})$.

\section{Bioluminescence assay}

Bioluminescence assay was performed using the CheckLite $^{\text {TM }}$ AT100 kit (Kikkoman Biochemifa Company, Japan) with the improved pretreatment buffer for soy milk (SPB) according to the manual. SPB comprises 3\% EMULGEN 420 (polyoxyethylene oleyl ether, Kao Corporation, Japan), 2\% Tween 80 (Sigma-Aldrich, USA), $20 \mathrm{mM}$ Ethylene Glycol Bis (beta-aminoethylether)-N,N,N,N-tetraacetic Acid (EGTA), and $1 \mathrm{mM}$ Ethylenediaminetetraacetic acid (EDTA). SPB detaches extracellular ATP from suspended solid materials such as proteins and fibers. To compare the background bioluminescence created by extracellular ATP in conventional and pretreated bioluminescence assays, the two methods were investigated in parallel. For the pretreated assay, a $100 \mu \mathrm{l}$ aliquot of soy milk or bacterial cultures was mixed with $100 \mu \mathrm{I}$ SPB in an ATP-free disposable tube (Kikkoman Biochemifa Company, Japan). A one hundred microliter sample with no SPB was used for the conventional assay (control). To expel the extracellular ATP from the pretreated tube, 100 $\mu \mathrm{I}$ of ATP eliminating reagent (comprises ATP degrading enzymes, adenosine phosphate deaminase and apyrase) was added to the mixture, followed by the addition of $700 \mu \mathrm{l}$ (800 $\mu \mathrm{I}$ to the conventionallytreated tube) of dilution buffer and mixed. The ATP eliminating enzymatic reaction was allowed to proceed for $30 \mathrm{~min}$ at room temperature, then extracellular ATP was enzymatically degraded. Following this, $100 \mu \mathrm{l}$ of the mixture was poured into a new tube and was mixed with $100 \mu$ I of the ATP releasing reagent solution. Intracellular ATP was released from bacterial cells using the ATP releasing reagent solution, also inactivating the ATP eliminating enzymatic reaction. Luciferin-luciferase reagent HS solution $(100 \mu \mathrm{l})$ was added to the mixture and vortexed. Bioluminescence was measured immediately with a luminometer (Kikkoman Biochemifa Company, Lumitester C-100) and recorded in relative light units (RLU).

\section{Validation of bioluminescence assay}

The performance of the bioluminescence assay was estimated. A dose-response curve was prepared from serial dilutions $\left(10^{-1}\right.$ to $10^{-5}$, with aseptic soy milk as the diluting agent) of Bacillus sp. WO1 culture incubated in soy milk for $24 \mathrm{~h}$ at $35^{\circ} \mathrm{C}$. The serial dilutions were tested by the bioluminescence assay and plate count method as described above. Control bioluminescence intensities were obtained by the same SPB-buffered bioluminescence assay procedure but without spores. The average bioluminescence intensity of the control samples was considered as the background. Bioluminescence intensity above three times the background was considered as signals from positive, spore-contaminated samples.

\section{Data analysis}

The bioluminescence assay results (RLU) and plate counts (CFU/ml) were manually recoded on an Excel spread sheet (Microsoft). To prepare the doseresponse curve, the signals and the plate counts were converted to log RLU and log CFU/ml respectively. Correlation and linear regression were performed on RLU versus CFU/ml using Excel. To evaluate the positive agreement scores, positive plate counts and positive RLU were compared in each of the 20 tubes at each incubation time.

\section{RESULTS AND DISCUSSION}

\section{Background bioluminescence intensity of soy milk}

To evaluate the extent to which pretreatment can reduce the background bioluminescence (BL) intensity, the conventionally obtained BL intensity was compared with that of the improved method for seven 
different commercial soy milk products of different flavors (Fig.1). BL intensities (three independent assays) from conventional method were: Plain 1, 1,275 \pm 7 ; Tea, $330 \pm 41$; Sesame, $280 \pm 6$; Plain2, 54 \pm 1; Original, $324 \pm 6$; Coffee, 154 \pm 7; Cocoa, 175 \pm 36 RLU. Those derived from the SPB-buffered regime were: Plain 1, $65 \pm 5$; Tea, $23 \pm 10$; Sesame, $67 \pm 5$; Plain2, $20 \pm 3$; Original, $30 \pm 23$; Coffee, $28 \pm 2$; Cocoa, $25 \pm 6$ RLU. Clearly, pretreatment buffer applied to soy milk samples significantly reduced the BL intensity (by a factor of 20 in the case of Plain 1).

In previous studies, selecting appropriate detergents for sample components was shown to effectively decrease background ATP (Thore et al., 1975; Dexter et al., 2003). Furthermore, somatic cells have been identified as a potential noise source in milk bioluminescence assays (O'Toole, 1983). Commercially available nucleotide-releasing reagent for somatic cells, combined with filtration, has been used in ATP bioluminescence estimation of total bacterial count in raw milk (Samkutty et al., 2001). In the case of soy milk, little is known about background ATP. However, it may be presumed that soy milk contains fiber rather than somatic cells. Of the tested soy milk made from whole soy bean powder (Plain1 and Plain2), Plain 1

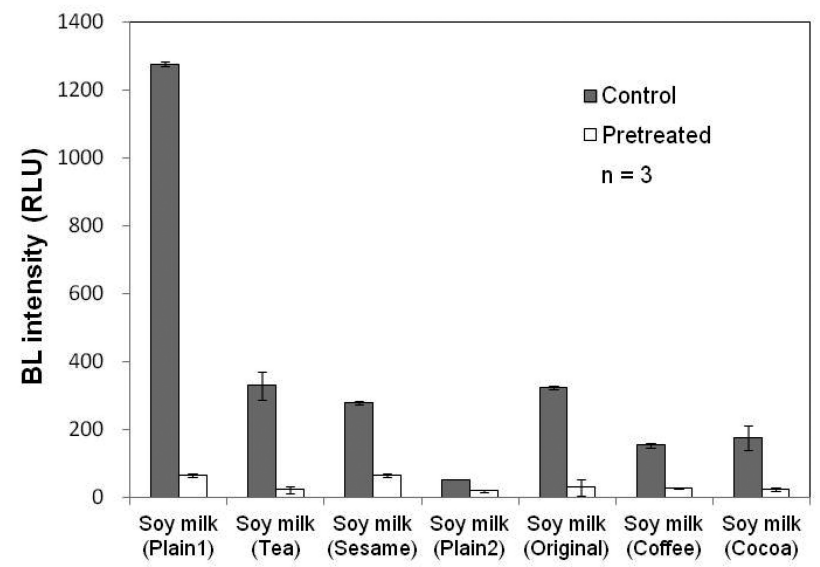

FIG. 1. Effects of the pretreatment method on the background bioluminescence (BL) intensity of soy milk samples. $B L$ is expressed in relative light units ( $R L U)$. generates an especially high background, suggesting a much higher fiber content for Plain1 than Plain2 (from which filtration residues "okara" have been removed). SPB contains two non-ionic detergents, EMULGEN 420 and Tween 80, with polyoxyethylene (PEO) chain lengths 13 and 20 oxyethylene units, respectively. Combining detergents of different PEO chain length appears to have significantly reduced the background levels. In fact, Tween 80 alone in the pretreatment buffer was ineffective at reducing the background (data not shown). From previous studies and the above considerations, we infer that SPB contains components that favor the detachment of extracellular ATP from suspended solid materials, including soy milk proteins and fibers.

\section{Influence of the pretreatment on bacterial BL intensity}

To confirm that pretreatment influences bacterial $B L$ intensity, vegetative cells of four spore forming bacterial strains were tested. In cultures of Bacillus sp., the ratio of BL intensities of the pretreated sample to the conventionally prepared sample ranged from 90.2 to $113.5 \%$ (Table 1). In other words, pretreatment did not significantly influence the bacterial BL intensity. Initially, we were concerned that the pretreatment regime, involving intensive detergent and vigorous mixing, would reduce the signal as well as the noise. However, the results reported in Fig. 1 and Table 1 indicate that the pretreatment method effectively reduces the background intensity while exerting negligible impact on the bacterial $B L$ intensity.

\section{Dose-response curve of the bioluminescence assay}

The dose-response curve of the assay was constructed from serial dilutions of a spore culture of Bacillus sp. W01. Fig. 2 shows the relationship between BL intensity and plate count for this species. A strong log-log relationship between the BL intensity $\mathrm{RLU}$ and plate count CFU/ml emerges. The linearity between RLU and CFU/ml for the tested strain is almost perfect $\left(R^{2}=0.999999\right)$. In the case of soy milk

TABLE 1. Influence of pretreatment on the bioluminescence intensity in Bacillus spp. cultures.

\begin{tabular}{|c|c|c|c|c|c|}
\hline \multirow[b]{2}{*}{ Strain } & \multicolumn{2}{|c|}{ Control } & \multicolumn{2}{|c|}{ Pretreated } & \multirow{2}{*}{$\begin{array}{c}\text { Influence of } \\
\text { pretreatment } \\
\text { on intensity }(\%)\end{array}$} \\
\hline & $\begin{array}{c}\text { BL intensity } \\
(R L U)\end{array}$ & CV $(\%)$ & $\begin{array}{c}\text { BL intensity } \\
(\mathrm{RLU})\end{array}$ & CV $(\%)$ & \\
\hline Bacillus subtilis ATCC6051 & $6.5 \times 10^{5}$ & 1.6 & $6.5 \times 10^{5}$ & 3.4 & 99.3 \\
\hline Bacillus licheniformis NBRC12200 & $4.8 \times 10^{5}$ & 5.0 & $4.3 \times 10^{5}$ & 5.4 & 90.2 \\
\hline Bacillus coagulans NBRC 12583 & $2.5 \times 10^{5}$ & 3.8 & $2.5 \times 10^{5}$ & 1.6 & 100.0 \\
\hline Bacillus megaterium NBRC15308 & $4.6 \times 10^{5}$ & 5.8 & $5.2 \times 10^{5}$ & 9.0 & 113.5 \\
\hline
\end{tabular}

a) Calculated as BL intensity (Pretreated) $\div$ BL intensity (Control) $\times 100$. 
plain 1, $195 \mathrm{RLU}$ is three times the mean background level (Fig. 1. Soy milk Plain1: background $65 \pm 5$ $R L U)$; thus samples showing $B L$ intensity above 195 $R L U$ were regarded as spore-positive. From the doseresponse curve and the imposed threshold at three times the background, the detection limit of the assay was estimated as $5.2 \times 10^{3} \mathrm{CFU} / \mathrm{ml}$.

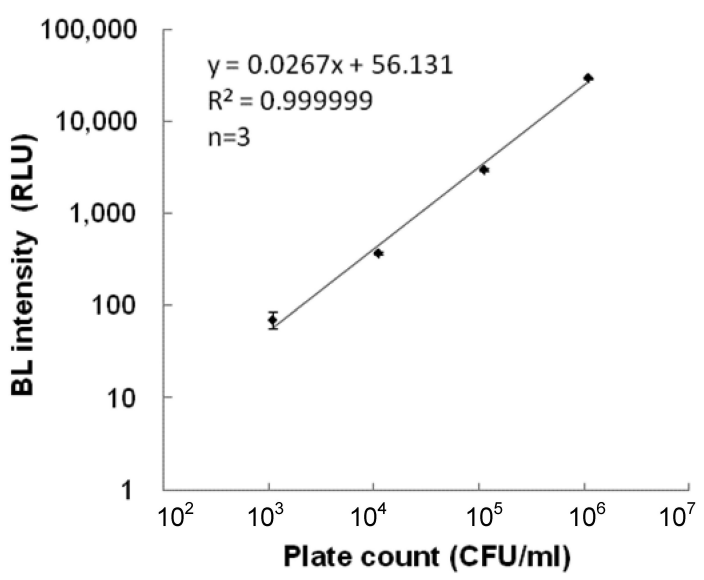

FIG. 2. Relationship between $B L$ intensity (relative light units) and the colony plate count (colony forming units per $\mathrm{ml}$ of inoculum) for Bacillus sp. WO1.

\section{Spike examination with the assay}

Table 2 compares the measured BL intensity and plate count from respective incubated soy milk samples. Twenty tubes were tested for each incubation period of $18,24,48$, and $72 \mathrm{~h}$ (18 and $24 \mathrm{~h}$ incubations were assayed from the same tubes).

After $18 \mathrm{~h}$ incubation, positive BL intensity and plate counts were obtained from 12 and 13 tubes, respectively. After $24 \mathrm{~h}$ incubation, instances of positive $\mathrm{BL}$ intensity matched the number of positive plate counts (13). Therefore, $65 \%$ of tubes (13/20) tested positive by both methods after $24 \mathrm{~h}$ incubation. After $48 \mathrm{~h}$ and $72 \mathrm{~h}$ incubation, positive BL intensities were obtained from 17 and 16 tubes, respectively, all of which also produced significant plate counts. At these late incubation times, proportions of positive results were $85 \%$ and $80 \%$ respectively, for both the bioluminescence assay and plate counting.

For ease of comparison, the results of Table 2 are summarized in Table 3. After $24 \mathrm{~h}$ incubation, the proportion of positive results (65\%) was lower than that at $48 \mathrm{~h}(85 \%)$ and $72 \mathrm{~h}(80 \%)$. The spore suspension used in this study was diluted to quite low numbers (1.6 CFU/tube) to mimic approximately aseptic conditions. Furthermore, the seven tubes that tested negative for bioluminescence intensity and plate count after $24 \mathrm{~h}$ remained negative even after $168 \mathrm{~h}$

TABLE 2. Comparison between measured $B L$ intensity and colony plate counts from soy milk samples in respective tubes.

\begin{tabular}{|c|c|c|c|c|c|c|c|c|c|c|}
\hline & \multicolumn{2}{|c|}{$18 \mathrm{~h}$} & \multicolumn{2}{|c|}{$24 \mathrm{~h}$} & & \multicolumn{2}{|c|}{$48 \mathrm{~h}$} & & \multicolumn{2}{|c|}{$72 \mathrm{~h}$} \\
\hline & $\begin{array}{c}B L \\
\text { intensity } \\
(R L U)\end{array}$ & $\begin{array}{c}\text { Plate } \\
\text { count } \\
(\mathrm{CFU} / \mathrm{ml})\end{array}$ & $\begin{array}{c}B L \\
\text { intensity } \\
(R L U)\end{array}$ & $\begin{array}{c}\text { Plate } \\
\text { count } \\
(\mathrm{CFU} / \mathrm{ml})\end{array}$ & & $\begin{array}{c}\mathrm{BL} \\
\text { intensity } \\
(\mathrm{RLU})\end{array}$ & $\begin{array}{c}\text { Plate } \\
\text { count } \\
(\mathrm{CFU} / \mathrm{ml})\end{array}$ & & $\begin{array}{c}B L \\
\text { intensity } \\
(R L U)\end{array}$ & $\begin{array}{c}\text { Plate } \\
\text { count } \\
(\mathrm{CFU} / \mathrm{ml})\end{array}$ \\
\hline No.1 & 919,663 & $4.1 \times 10^{7}$ & S.O. & $1.1 \times 10^{8}$ & No.21 & S.O. & $3.1 \times 10^{7}$ & No.41 & S.O. & $2.6 \times 10^{7}$ \\
\hline No.2 & 77,769 & $6.9 \times 10^{6}$ & S.O. & $7.5 \times 10^{7}$ & No.22 & 2,477 & $9.5 \times 10^{4}$ & No.42 & S.O. & $3.1 \times 10^{7}$ \\
\hline No.3 & S.O. & $5.6 \times 10^{7}$ & S.O. & $9.0 \times 10^{7}$ & No.23 & S.O. & $4.1 \times 10^{7}$ & No.43 & 78 & $<20$ \\
\hline No.4 & 619,609 & $2.7 \times 10^{7}$ & S.O. & $8.8 \times 10^{7}$ & No.24 & S.O. & $4.1 \times 10^{7}$ & No.44 & S.O. & $3.1 \times 10^{7}$ \\
\hline No.5 & S.O & $5.3 \times 10^{7}$ & S.O. & $9.6 \times 10^{7}$ & No.25 & S.O. & $3.8 \times 10^{7}$ & No.45 & S.O. & $2.2 \times 10^{7}$ \\
\hline No.6 & 58 & $<20$ & 41 & $<20$ & No.26 & S.O. & $4.1 \times 10^{7}$ & No.46 & S.O. & $2.4 \times 10^{7}$ \\
\hline No.7 & 941,748 & $6.6 \times 10^{7}$ & S.O. & $1.0 \times 10^{7}$ & No.27 & S.O. & $3.5 \times 10^{7}$ & No.47 & S.O. & $3.1 \times 10^{7}$ \\
\hline No.8 & 575,146 & $3.4 \times 10^{7}$ & S.O. & $6.1 \times 10^{7}$ & No.28 & S.O. & $3.8 \times 10^{7}$ & No.48 & 50 & $<20$ \\
\hline No.9 & 773,913 & $4.1 \times 10^{7}$ & S.O. & $8.1 \times 10^{7}$ & No.29 & S.O. & $3.6 \times 10^{7}$ & No.49 & S.O. & $2.7 \times 10^{7}$ \\
\hline No. 10 & 52 & $<20$ & 41 & $<20$ & No.30 & S.O. & $4.0 \times 10^{7}$ & No.50 & S.O. & $3.0 \times 10^{7}$ \\
\hline No.11 & 50 & $<20$ & 46 & $<20$ & No.31 & S.O. & $2.5 \times 10^{7}$ & No.51 & S.O. & $2.3 \times 10^{7}$ \\
\hline No. 12 & 55 & $<20$ & 38 & $<20$ & No.32 & S.O. & $4.0 \times 10^{7}$ & No.52 & S.O. & $2.4 \times 10^{7}$ \\
\hline No.13 & S.O. & $4.7 \times 10^{7}$ & S.O. & $6.6 \times 10^{7}$ & No.33 & S.O. & $8.2 \times 10^{7}$ & No.53 & S.O. & $2.5 \times 10^{7}$ \\
\hline No. 14 & 52 & $<20$ & 54 & $<20$ & No.34 & 51 & $<20$ & No.54 & S.O. & $2.6 \times 10^{7}$ \\
\hline No. 15 & 297,971 & $4.6 \times 10^{7}$ & S.O. & $6.2 \times 10^{7}$ & No.35 & S.O. & $4.2 \times 10^{7}$ & No.55 & 48 & $<20$ \\
\hline No. 16 & 901,577 & $4.2 \times 10^{7}$ & S.O. & $7.3 \times 10^{7}$ & No.36 & S.O. & $3.4 \times 10^{7}$ & No.56 & S.O. & $2.8 \times 10^{7}$ \\
\hline No. 17 & 60 & $1.2 \times 10^{4}$ & 14,316 & $4.0 \times 10^{6}$ & No.37 & 43 & $<20$ & No.57 & 54 & $<20$ \\
\hline No. 18 & 783,686 & $3.4 \times 10^{7}$ & S.O. & $7.4 \times 10^{7}$ & No.38 & S.O. & $3.6 \times 10^{7}$ & No.58 & S.O. & $2.8 \times 10^{7}$ \\
\hline No.19 & 49 & $<20$ & 49 & $<20$ & No.39 & 43 & $<20$ & No.59 & S.O. & $2.4 \times 10^{7}$ \\
\hline No.20 & 50 & $<20$ & 49 & $<20$ & No.40 & S.O. & $3.1 \times 10^{7}$ & No.60 & S.O. & $2.6 \times 10^{7}$ \\
\hline
\end{tabular}

S.O. denotes over scale (above 1,000,000 RLU, the upper detection limit of the luminometer). 
TABLE 3. Summary of comparisons between the improved ATP assay and colony counts from soy milk samples in tubes.

\begin{tabular}{|c|c|c|c|c|c|c|c|c|}
\hline & \multicolumn{2}{|c|}{$18 \mathrm{~h}$} & \multicolumn{2}{|c|}{$24 \mathrm{~h}$} & \multicolumn{2}{|c|}{$48 \mathrm{~h}$} & \multicolumn{2}{|c|}{$72 \mathrm{~h}$} \\
\hline & $\begin{array}{l}\text { ATP } \\
\text { Method }\end{array}$ & $\begin{array}{l}\text { Plate } \\
\text { Count } \\
\text { Method }\end{array}$ & $\begin{array}{l}\text { ATP } \\
\text { Method }\end{array}$ & $\begin{array}{l}\text { Plate } \\
\text { Count } \\
\text { Method }\end{array}$ & $\begin{array}{l}\text { ATP } \\
\text { Method }\end{array}$ & $\begin{array}{l}\text { Plate } \\
\text { Count } \\
\text { Method }\end{array}$ & $\begin{array}{l}\text { ATP } \\
\text { Method }\end{array}$ & $\begin{array}{l}\text { Plate } \\
\text { Count } \\
\text { Method }\end{array}$ \\
\hline Positive numbers & $12 / 20$ & $13 / 20$ & $13 / 20$ & $13 / 20$ & $17 / 20$ & $17 / 20$ & $16 / 20$ & $16 / 20$ \\
\hline Positive rate (\%) & 60.0 & 65.0 & 65.0 & 65.0 & 85.0 & 85.0 & 80.0 & 80.0 \\
\hline $\begin{array}{l}\text { Positive } \\
\text { agreement rate (\%) }\end{array}$ & \multicolumn{2}{|c|}{92.3} & \multicolumn{2}{|c|}{100.0} & \multicolumn{2}{|c|}{100.0} & \multicolumn{2}{|c|}{100.0} \\
\hline
\end{tabular}

incubation (data not shown). Therefore, differences between proportions of positives likely arise from variability in inoculated spore numbers. We conclude that the improved bioluminescence assay enables easy and rapid (within $24 \mathrm{~h}$ ) detection of contaminated soy milk samples.

Few published reports for rapid detection of bacterial contamination in soy milk exist (Pascall et al., 2006). Therefore, novel rapid detection methods or systems that can reliably confirm the sterility of soy milk products are essential to the beverage and food industries. In our estimation, the use of bioluminescence in aseptic soy milk testing has been hampered by the high concentration of the attached ATP in soy.

In the present study, we have demonstrated that improved bioluminescence techniques offer rapid and sensitive means to detect bacterial contamination in soy milk. Newly developed SPB effectively reduces background noise while leaving the bacterial signal intact. This paper is the first report of the application of the bioluminescence assay to soy milk. High levels of intractable background ATP likely exist in many food types. Further research into pretreatment is required before bioluminescence assay can be customized to specific foods. However, we propose that, by modifying our pretreatment technique, background bioluminescence from many types of foods and beverages could be reduced, thus expanding the applicability of the bioluminescence assay.

\section{REFERENCES}

Chen, F.C., and Godwin, S.L. (2006) Comparison of a rapid ATP bioluminescence assay and standard plate count methods for assessing microbial contamination of consumers' refrigerators. J. Food. Prot., 69, 2534-2538.

Clarkson, T.B., Anthony, M.S., and Hughes, C.L. Jr (1995) Estrogenic soybean isoflavones and chronic disease Risks and benefits. Trends. Endocrinol. Metab., 6, 11-16.

Dexter, S.J., Camara, M., Davies, M., and Shakesheff, K.M. (2003) Development of a bioluminescent ATP assay to quantify mammalian and bacterial cell number from a mixed population. Biomaterials, 24, 27-34.

Gavin, E.A., and Weddig, L.M. (1995) Introduction, p. 6. In
A.Gavin and L. M. Weddig (ed.), Canned Foods.

Golbitz, P. (1995) Traditional soyfoods: processing and products. J. Nutr., 125, 570S-572S.

Hattori, N., Nakajima, M.O., O'Hara, K., and Sawai, T. (1998) Novel antibiotic susceptibility tests by the ATPbioluminescence method using filamentous cell treatment. Antimicrob. Agents. Chemother., 42, 1406-1411.

Hattori, N., Sakakibara, T., Kajiyama, N., Igarashi, T., Maeda, M., and Murakami, S. (2003) Enhanced microbial biomass assay using mutant luciferase resistant to benzalkonium chloride. Anal. Biochem., 319, 287-295.

Knight, D.C., and Eden, J.A. (1996) A review of the clinical effects of phytoestrogens. Obstet. Gynecol., 87, 897-904.

Kwok, K.C., and Niranjan, K. (1995) Review: Effect of thermal processing on soymilk. Int. J. Food. Sci. Technol., 30, 263-295.

Lee, H.P., Gourley, L., Duffy, S.W., Esteve, J., Lee, J., and Day, N.E. (1991) Dietary effects on breast-cancer risk in Singapore. Lancet, 337, 1197-1200.

O'Toole, D.K. (1983) Methods for the direct and indirect assessment of the bacterial content of milk. J. Appl. Bacteriol., 55, 187-201.

Pascall, M.A., Ravishankar, S., Ghiron, K., Lee, B.T., and Johannessen, J.N. (2006) Evaluation of magnetic resonance for detection of bacterial contamination in lowacid, shelf-stable packaged soymilk. J. Food. Prot., 69, 1668-1674.

Peterson, G., and Barnes, S. (1991) Genistein inhibition of the growth of human breast cancer cells: independence from estrogen receptors and the multi-drug resistance gene. Biochem. Biophys. Res. Commun., 179, 661-667.

Sakakibara, T., Murakami, S., Hattori, N., Nakajima, M., and Imai, K. (1997) Enzymatic treatment to eliminate the extracellular ATP for improving the detectability of bacterial intracellular ATP. Anal. Biochem., 250, 157-161.

Samkutty, P.J., Gough, R.H., Adkinson, R.W., and McGrew, P. (2001) Rapid assessment of the bacteriological quality of raw milk using ATP bioluminescence. J. Food. Prot., 64, 208-212.

Sato, J. (2010) Distribution of filamentous fungi in a manufacturing factory for plastic caps for soft drinks. Biocontrol. Sci., 15, 87-90.

Shirai, A., Sumitomo, T., Kurimoto, M., Maseda, H., and Kourai, H. (2009) The mode of the antifungal activity of gemini-pyridinium salt against yeast. Biocontrol Sci., 14, 13-20.

Steve, C. (1989) Proceedings of the World Congress on Vegetable Protein Utilization in Human Foods and Animal Feedstuffs. Chapter 54, 341-352, The American Oil Chemists Society, Illinois.

Thore, A., Ansehn, S., Lundin, A., and Bergman, S. (1975) 
Detection of bacteriuria by luciferase assay of adenosine triphosphate. J. Clin. Microbiol., 1, 1-8.

Ukuku, D.O., Pilizota, V., and Sapers, G.M. (2001) Bioluminescence ATP assay for estimating total plate counts of surface microflora of whole cantaloupe and determining efficacy of washing treatments. J. Food. Prot., 64, 813-819.

Ukuku, D.O., Sapers, G.M., and Fett, W.F. (2005) ATP bio- luminescence assay for estimation of microbial populations of fresh-cut melon. J. Food. Prot., 68, 2427-2432.

Venkateswaran, K., Hattori, N., La, Duc M.T., and Kern, R. (2003) ATP as a biomarker of viable microorganisms in clean-room facilities. J. Microbiol. Methods, 52, 367-377.

Xiao, C.W. (2008) Health effects of soy protein and isoflavones in humans. J. Nutr., 138, 1244S-1249S. 